\title{
Avaliação da viabilidade espermática de sêmen caprino criopreservado em meio ACP-101c e TRIS acrescido de gema de ovo de Numida meleagris
}

Evaluation of sperm viability of cryopreserved goat semen in ACP-101c and TRIS medium plus

Numida meleagris egg yolk

Evaluación de la viabilidad espermática de semen de cabra criopreservado en medio ACP-101c y

TRIS más yema de huevo Numida meleagris

Recebido: 20/10/2021 | Revisado: 28/10/2021 | Aceito: 29/10/2021 | Publicado: 01/11/2021

Laércio Fontinele Bandeira de Macêdo ORCID: https://orcid.org/0000-0002-5417-3033 Universidade Estadual do Ceará, Brasil E-mail: laerciofbj@hotmail.com

Letícia Soares de Araújo Teixeira ORCID: https://orcid.org/0000-0003-1630-6904 Universidade Federal do Piauí, Brasil E-mail: leticiasoateixeira@gmail.com

Wcleuden Matias Nascimento

ORCID: https://orcid.org/0000-0002-0264-2942 Universidade Estadual do Ceará, Brasil E-mail: wcleudemmatias@hotmail.com

Clarissa de Castro e Braga

ORCID: https://orcid.org/0000-0002-2658-9111 Universidade Federal do Piauí, Brasil

E-mail: clah_1995@hotmail.com

Kenney de Paiva Porfírio

ORCID: https://orcid.org/0000-0001-5195-0434 Universidade Federal do Piaú, Brasil

E-mail: kenney@ufpi.edu.br

Francisca Kelly dos Santos Silva ORCID: https://orcid.org/0000-0002-2084-584X Universidade Federal do Piauí, Brasil

E-mail: fkelly2209@gmail.com

Sara Camila da Silveira Costa ORCID: https://orcid.org/0000-0003-0381-0116 Universidade Federal do Piauí, Brasil E-mail: saracostapink@hotmail.com

Louis Henrique Miyauchi Silva ORCID: https://orcid.org/0000-0002-5653-2263 Universidade Federal do Piauí, Brasil E-mail: louishms@hotmail.com.br Rômulo José Vieira

ORCID: https://orcid.org/0000-0002-4154-3808 Universidade Federal do Piauí, Brasil E-mail: rvieirasb@yahoo.com.br

Cristiane Clemente de Mello Salgueiro ORCID: https://orcid.org/0000-0003-0071-4030 Universidade Estadual do Ceará, Brasil E-mail: cristiane.mello@uece.br José Ferreira Nunes

ORCID: https://orcid.org/0000-0003-1189-0937 Universidade Estadual do Ceará, Brasil E-mail: nunesuece@gmail.com

Nildene Silva Andradre Bandeira ORCID: https://orcid.org/0000-0003-4723-8983 Faculdade Santo Agostinho, Brasil E-mail: nildeneandrade@hotmail.com

Fabrício Pires de Moura do Amaral ORCID: https://orcid.org/0000-0001-6187-2206

Universidade Estadual do Piauí, Brasil E-mail: fabricio34amaral@gmail.com 


\author{
Ana Lys Bezerra Barradas Mineiro \\ ORCID: https://orcid.org/ 0000-0002-3997-1694 \\ Universidade Federal do Piauí, Brasil \\ E-mail: lysbarradas@yahoo.com.br \\ Janaina de Fátima Saraiva Cardoso \\ ORCID: https://orcid.org/0000-0002-4484-4403 \\ Universidade Federal do Piauí, Brasil \\ E-mail: janainadefatima @ hotmail.com \\ Ney Rômulo de Oliveira Paula \\ ORCID: https://orcid.org/0000-0002-0484-3748 \\ Universidade Federal do Piauí, Brasil \\ E-mail: neyromulo@ufpi.edu.br
}

\begin{abstract}
Resumo
Um meio diluente ideal para a criopreservação seminal deve suprir as células espermáticas com energia, proteção e manutenção de um ambiente adequado à sua sobrevivência. Objetivou-se avaliar a integridade in vitro do sêmen caprino criopreservado em meio ACP-101 $\mathrm{c}^{\circledR}$ associado à gema de ovo de Numida meleagris, por meio de duas técnicas de análise individual da célula espermática. Foram colhidos 15 ejaculados de cinco caprinos, com auxílio de uma vagina artificial. Os ejaculados foram reunidos em um pool, e dividido em 12 grupos, sendo dois grupos controles: GC1 TRIS, com adição 2,5\% da gema de ovo de Gallus gallus domesticus GOGD, GC2 ACP-101c ${ }^{\circledR}$, com adição 2,5\% da gema de ovo de Gallus gallus domesticus GOGD e dez grupos experimentais GE, contendo a adição da gema de ovo de Numida meleagris. Seguidamente, as alíquotas foram envasadas em palhetas francesas de $0,25 \mathrm{~mL}$ e congeladas com auxílio do aparelho TK $3000^{\circledR}$ e armazenadas em nitrogênio líquido. Amostras foram descongeladas após sete dias e avaliadas quanto à integridade do DNA e quanto a sua ultraestrutura individual, por meio do teste cometa e microscopia eletrônica de transmissão, respectivamente. Nos resultados obtidos pelo teste cometa, não foi evidenciado diferença estatística quanto ao comprimento da cauda, entre os grupos TRIS acrescido de GONM, nas concentrações de 2,5\%, $5 \%$ e $10 \%$ em relação ao grupo controle TRIS 2,5\% de GOGD. Também não houve diferença estatística quanto ao percentual de fragmentação de DNA na cauda, nos grupos TRIS com 2,5\%; $5 \%$; e $20 \%$ de GONM em comparação ao grupo controle TRIS 2,5\% GOGD (P>0,05). Os grupos $\mathrm{ACP}^{\circledR}{ }^{\circledR}$ com $10 \%, 15 \%$ e $20 \%$ de GONM apresentaram maior comprimento de cauda quando comparados aos grupos ACP com 2,5\% e 5\% de GONM e grupo controle $\left(\mathrm{ACP}^{\circledR} 2,5 \%\right.$ de GOGD). Na análise ultraestrutural o grupo $\mathrm{ACP}^{\circledR}$ com $10 \%$ de GONM, destacou-se com melhor integridade celular frente aos demais grupos, inclusive, frente às amostras avaliadas do grupo controle. Dessa forma, conclui-se que a gema de ovo de Numida meleagris, como crioprotetor externo de membrana, acrescida aos diluentes ACP-101c ${ }^{\circledR}$ ou TRIS, pode reduzir os danos causados durante o processo de criopreservação do sêmen caprino.
\end{abstract}

Palavras-chave: Bode; Teste cometa; Microscopia eletrônica de transmissão; $\mathrm{ACP}^{\circledR}$.

\begin{abstract}
An ideal diluent medium for seminal cryopreservation must supply sperm cells with energy, protection and maintenance of an environment suitable for their survival. The objective of this study was to evaluate the in vitro integrity of goat semen cryopreserved in ACP-101c ${ }^{\circledR}$ medium associated with the egg yolk of Numida meleagris, through two techniques of individual sperm cell analysis. Fifteen ejaculates from five goats were collected with the aid of an artificial vagina. Ejaculates were collected in a pool and divided into 12 groups, two control groups: GC1 TRIS, with $2.5 \%$ addition of the egg yolk of Gallus gallus domesticus GOGD, GC2 ACP-101c ${ }^{\circledR}$, with $2.5 \%$ addition from the egg yolk of Gallus gallus domesticus GOGD and ten experimental groups GE, containing the addition of the egg yolk of Numida meleagris. Afterwards, the aliquots were bottled in French $0.25 \mathrm{~mL}$ straws and frozen with the aid of the TK $3000^{\circledR}$ device and stored in liquid nitrogen. Samples were thawed after seven days and evaluated for DNA integrity and for their individual ultrastructure, using the comet test and transmission electron microscopy, respectively. In the results obtained by the comet test, there was no statistical difference in tail length between the TRIS groups plus GONM, at concentrations of $2.5 \%, 5 \%$ and $10 \%$ compared to the control group TRIS $2.5 \%$ of GOGD. There was also no statistical difference regarding the percentage of DNA fragmentation in the tail, in the TRIS groups with 2.5\%; 5\%; and 20\% GONM compared to the TRIS control group 2.5\% GOGD (P>0.05). The $\mathrm{ACP}^{\circledR}$ groups with $10 \%, 15 \%$ and $20 \%$ GONM had greater tail length when compared to the $\mathrm{ACP}^{\circledR}$ groups with $2.5 \%$ and 5\% GONM and control group (ACP ${ }^{\circledR} 2.5 \%$ GOGD). In the ultrastructural analysis, the $\mathrm{ACP}^{\circledR}$ group with $10 \%$ GONM stood out with better cellular integrity compared to the other groups, even compared to the evaluated samples of the control group. Thus, it is concluded that the egg yolk of Numida meleagris, as an external membrane cryoprotectant, added to ACP-101c ${ }^{\circledR}$ or TRIS extenders, can reduce the damage caused during the process of cryopreservation of goat semen.
\end{abstract}

Keywords: Buck; Comet test; Transmission electron microscopy; $\mathrm{ACP}^{\circledR}$. 


\section{Resumen}

Un medio diluyente ideal para la criopreservación seminal debe proporcionar a los espermatozoides energía, protección y mantenimiento de un entorno adecuado para la supervivencia de los espermatozoides. El objetivo de este estudio fue evaluar la integridad in vitro de semen de cabra criopreservado en medio ACP-101c ${ }^{\circledR}$ asociado a la yema de huevo de Numida meleagris, mediante das técnicas de análisis de espermatozoides individuales. Se recolectaron quince eyaculados de cinco cabras con la ayuda de una vagina artificial. Los eyaculados se recolectaron en un pool y se dividieron en 12 grupos, dos grupos de control: GC1 TRIS, con adición al $2.5 \%$ de la yema de huevo de Gallus gallus domesticus GOGD, GC2 ACP-101c ${ }^{\circledR}$, con adición al $2.5 \%$ de la yema de huevo de Gallus gallus domesticus GOGD y diez grupos experimentales GE, que contienen la adición de la yema de huevo de Numida meleagris. Posteriormente, las alícuotas se llenaron en pajitas francesas de $0,25 \mathrm{~mL}$ y se congelaron con la ayuda del dispositivo TK3000® y se almacenaron en nitrógeno líquido. Las muestras se descongelaron después de siete días y se evaluó la integridad del ADN y su ultraestructura individual, utilizando la prueba del cometa y la microscopía electrónica de transmisión, respectivamente. En los resultados obtenidos por la prueba del cometa, no hubo diferencia estadística en la longitud de la cola entre los grupos TRIS más GONM, a concentraciones de $2.5 \%, 5 \%$ y $10 \%$ en comparación con el grupo control TRIS $2.5 \%$ de GOGD. Tampoco hubo diferencia estadística con respecto al porcentaje de fragmentación del ADN en la cola, en los grupos TRIS con 2.5\%; 5\%; y 20\% de GONM en comparación con el grupo de control de TRIS 2,5\% de GOGD (P> 0,05). Los grupos de $\mathrm{ACP}^{\circledR}$ con $10 \%, 15 \%$ y $20 \%$ de GONM tenían una mayor longitud de cola en comparación con los grupos de $\mathrm{ACP}^{\circledR}$ con 2,5\% y 5\% de GONM y el grupo de control $\left(\mathrm{ACP}^{\circledR} 2,5 \%\right.$ de GOGD). En el análisis ultraestructural, el grupo $\mathrm{ACP}^{\circledR}$ con $10 \%$ de GONM se destacó con mejor integridad celular en comparación con los otros grupos, incluso en comparación con las muestras evaluadas del grupo control. Así, se concluye que la yema de huevo de Numida meleagris, como crioprotector de membrana externa, agregado a los extensores ACP-101 ${ }^{\circledR}$ o TRIS, puede reducir el daño causado durante el proceso de criopreservación de semen de cabra.

Palabras clave: Cabra; Ensayo de cometas; Microscopía electrónica de transmisión; ACP ${ }^{\circledR}$.

\section{Introdução}

Dentre as biotecnologias aplicadas a reprodução animal, as biotécnicas aplicadas ao sêmen são as mais utilizadas principalmente, nas espécies: bovina, caprina e ovina. Uma vez que o sêmen é utilizado para a realização praticamente de todas as outras biotecnologias reprodutivas, como, por exemplo, a produção in vitro de embriões, produção in vivo de embriões, inseminação artificial e entre outras (Qin et al., 2018).

Nesse contexto, o sêmen vem sendo objetivo de estudo em muitos trabalhos científicos na área de reprodução animal. E, devido às pesquisas já realizadas ao longo do tempo, foram desenvolvidos inúmeros métodos para a avaliação do sêmen, a fim de testificar a viabilidade das células espermáticas, contribuindo para a eficiência das biotecnologias reprodutivas (Qin et al., 2018).

O teste cometa é um método de eletroforese em microgel para detecção e quantificação de fragmentações nas moléculas de DNA, em células individuais, usando microscopia e pH alcalino (pH > 13) (Park; Choi, 2007; Zaia, 2015). Devido as suas particularidades, o teste cometa vem sendo utilizado para avaliar a integridade do DNA de células espermáticas oriundas de sêmen animal criopreservado.

Ademais a microscopia eletrônica de transmissão (MET) é uma ferramenta muito utilizada para determinar o tamanho e a forma das estruturas inorgânicas e biológicas baseada na interação dos elétrons incidentes sobre a matéria. É uma técnica de grande relevância devido à possibilidade de avaliação das estruturas da célula (organelas e membranas) espermática em uma escala muito reduzida, o que favorece a visualização de alterações não observadas nos testes comuns por meio da microscopia óptica (Silva; Guerra, 2011).

Além disso, vale ressaltar que a escolha de um bom meio diluente é essencial para conferir proteção às células espermáticas protegendo-as durante o processo de criopreservação, por isso, são constituídos de ingredientes básicos, como substratos energéticos, tampões e componentes contra danos criogênicos (Cavalcante et al., 2014). E, devido a isso, a determinação de meios diluentes mais eficazes e que contenham ingredientes mais selecionados, tem sido foco de muitas pesquisas científicas. 
Dentre os meios diluentes já utilizados, pode-se citar a água de coco em pó $\left(\mathrm{ACP}^{\circledR}\right)$, tris gema, tris glicose gema, leite desnatado e entre outros (Salgueiro et al., 2012). No entanto, ainda não há relatos na literatura sobre a elaboração de um meio diluente seminal a base de gema de ovo de Numida meleagris, fato este que impulsionou a realização deste estudo. Tendo em vista, colaborar com os trabalhos já realizados.

Nesse sentido, objetivou-se, por meio deste estudo, avaliar a integridade in vitro do sêmen caprino criopreservado em meio ACP-101 ${ }^{\circledR}$ e TRIS acrescidos de um componente orgânico ainda não utilizado, a gema de ovo de Numida meleagris, por meio de duas técnicas de análise individual da célula espermática.

\section{Material e métodos}

\section{1 Ética na pesquisa animal}

O projeto foi avaliado e aprovado pela Comissão de Ética no Uso de Animais da Universidade Estadual do Piauí (CEUA/UESPI), sob o número de protocolo 07614/2018, em 20/07/2018. Para fins de pesquisa científica, encontra-se de acordo com os preceitos da Lei $\mathrm{N}^{\circ} 11.794$, de 08 de outubro de 2008, Decreto $\mathrm{N}^{\circ} 6.899$, de 15 de julho de 2009, e com as normas editadas pelo Conselho Nacional de Controle de Experimentação Animal (CONCEA).

\subsection{Animais utilizados e local de realização do estudo}

A pesquisa foi desenvolvida no setor de reprodução animal, da Universidade Federal do Piauí, Campus da Socopo, Teresina, Piauí, Brasil. Cujas coordenadas geográficas são: $5^{\circ}$ 03' 23,1”' de Latitude Sul e 42 47’ 27,9’' de Longitude Oeste, com altitude média de 72,7 metros.

Foram utilizados cinco reprodutores da espécie caprina, raça Anglo Nubiana, puros de origem, com idade média de quatro anos, clinicamente saudáveis e com escore de condição corporal de 3,5 numa escala de (0-5). Os animais utilizados foram provenientes de uma fazenda localizada no município de Campo Maior, no Estado do Piaú, cujas coordenadas geográficas são: Latitude $4^{\circ} 51^{\prime} 35,75^{\prime \prime} \mathrm{S}$ e Longitude $42^{\circ} 12^{\prime} 47,18^{\prime \prime}$ com altitude média de 129 metros. Os animais recebiam na alimentação diária: volumoso (Pennisetum purpureum Schum), concentrado comercial (ração peletizada com teor de $20 \%$ proteína, $300 \mathrm{~g} / \mathrm{animal} / \mathrm{dia}$ ), sal mineral específico para a espécie caprina (Caprinofós ${ }^{\circledR}$ ) e água a vontade.

Os reprodutores foram submetidos ao exame clínico reprodutivo, visando a avaliação da higidez geral e do aparelho reprodutivo, seguindo os critérios estabelecidos pelo Colégio Brasileiro de Reprodução Animal (CBRA, 2013).

\subsection{Avaliação bromatológica da gema de ovo da galinha d'Angola (Numida meleagris)}

Foram utilizados ovos de Numida meleagris, criadas em sistema extensivo, com postura em intervalo médio de cinco dias, provenientes de produtores rurais da microrregião de Campo Maior-PI. As aves recebiam como alimento sementes, insetos, grãos de milho e matéria seca de gramíneas nativas de capim mimoso (Axonopus purpusii Chas) e outras espécies Mésosetum, Axonopus, Pás palum, Panicum e Eriochloqde. Além disso, recebiam concentrados energéticos e proteicos de forma sólida em comedouros e disponibilidade de água ad libitum.

As análises bromatológicas foram realizadas na Universidade Federal do Piauí (UFPI), no Centro de Ciências da Saúde (CCS), Departamento de Nutrição, especificamente no Laboratório de Bromatologia e Bioquímica de Alimentos (LBROMBIOQ) e no Laboratório de Desenvolvimento de Produtos e Análise Sensorial de Alimentos (LASA).

Neste estudo, foram realizadas as seguintes análises bromatológicas: matéria seca, cinza, extrato estéreo, lipídio, carboidratos, proteínas e determinação de umidade.

O valor calórico do "nugget" em estudo foi calculado utilizando-se os fatores de conversão de ATWATER: 4 kcal/g para proteínas, $4 \mathrm{kcal} / \mathrm{g}$ para carboidratos e $9 \mathrm{kcal} / \mathrm{g}$ para lipídios (Watt e Merrill, 1963). Posteriormente, os teores de 
carotenoides totais foram determinados de acordo com a metodologia de Alvarez-Suarez et al. (2011), utilizando o solvente acetona/hexano e todos os extratos foram elaborados de acordo com a metodologia proposta por Rufino et al. (2010).

Por fim, a atividade antioxidante foi determinada pelo método de captura de radicais, utilizando o radical DPPH (2,2difenil-1-picril-hidrazil).

\subsection{Colheita de sêmen e avaliação espermática}

Cada reprodutor foi submetido a quinze colheitas de sêmen, com intervalos de quinze dias, para que tivessem um período de descanso após cada colheita. Inicialmente, o prepúcio dos reprodutores foi devidamente higienizado, a fim de remover as impurezas com o auxílio de solução fisiológica a $0,9 \%$ e papel toalha. As colheitas foram realizadas pelo método de vagina artificial, específica para pequenos ruminantes, aquecida a uma temperatura de $38^{\circ} \mathrm{C}$ acoplada a um tubo coletor graduado tipo Falcon (CBRA, 2013). Uma cabra em estro induzido foi utilizada durante as colheitas. Após cada colheita, o ejaculado foi protegido da incidência direta de luz solar, transportado ao laboratório e mantido em banho Maria a $37{ }^{\circ} \mathrm{C}$ (CBRA, 2013; Quin et al., 2018).

Seguidamente, foram realizadas as avaliações subjetivas macroscópicas do ejaculado, como, por exemplo, volume, cor e aspecto. Procedeu-se, sequencialmente, as avaliações dos parâmetros espermáticos, como: turbilhonamento, motilidade, vigor, morfologia espermática e concentração espermática (CBRA, 2013).

Foi utilizado um microscópio óptico (aumento de 400x) para avaliar a motilidade total (MT; escala de 0-100\%) e vigor espermático (0-5), sendo depositada uma gota de sêmen entre lâmina e lamínula previamente aquecidas e mantidas a 37 ${ }^{\circ} \mathrm{C}$. Na realização da análise morfológica das células espermáticas foram contados 200 espermatozoides por lâmina, em microscópio óptico, no aumento de 400x.

Para determinação da concentração espermática, o sêmen foi diluído em solução formol-salina (1: 200), e a contagem realizada em câmara de Neubauer com auxílio de um microscópio no aumento de 400x (CBRA, 2013; Quin et al., 2018).

\subsection{Formação dos grupos experimentais}

Os ejaculados colhidos foram reunidos em um pool e a concentração espermática foi avaliada em câmara de Neubauer. A taxa de diluição foi ajustada para uma concentração final de 320 milhões de espermatozoides $/ \mathrm{mL}$.

O pool foi dividido em doze alíquotas de igual volume, com no mínimo cinco mililitros de sêmen e diluídas em dois meios diluentes para criopreservação, TRIS e $\mathrm{ACP}^{\circledR}$. Seguidamente, foram formados os seguintes grupos: dois grupos controles (GC1 e GC2), contendo adição da gema de ovo de galinha doméstica (Gallus gallus domesticus), sendo o GC1 contendo TRIS 2,5\% de gema de ovo de galinha doméstica (GOGD) e GC2 contendo ACP ${ }^{\circledR} 2,5 \%$ de gema de ovo de galinha doméstica (GOGD) (tabela 1). E um total de dez grupos experimentais distribuídos entre os dois meios diluentes de criopreservação - TRIS e $\mathrm{ACP}^{\circledR}$, diferindo dos GC por conter a adição de um ingrediente nunca testado, a gema de ovo da galinha d'Angola (Numida meleagris). Vale ressaltar que os grupos experimentais foram divididos em dez concentrações distintas de gema de ovo de Numida meleagris, a saber: TRIS 2,5\% de gema de ovo de Numida meleagris (GONM); TRIS 5\% de GONM; TRIS 10\% de GONM; TRIS 15\% de GONM; TRIS 20\% de GONM; ACP ${ }^{\circledR} 2,5 \%$ de GONM; ACP ${ }^{\circledR} 5 \%$ de GONM; $\mathrm{ACP}^{\circledR} 10 \%$ de GONM; $\mathrm{ACP}^{\circledR} 15 \%$ de GONM; $\mathrm{ACP}^{\circledR} 20 \%$ de GONM (tabela 2). 
Tabela 1. Descrição dos grupos controles.

\begin{tabular}{|c|c|}
\hline Grupos Controles & Concentrações/Descrição \\
\hline GC1 - TRIS + 2,5\% & TRIS $+2,5 \%$ gema de ovo de Galus gallus domesticus \\
\hline \multicolumn{2}{|l|}{ GOGD } \\
\hline $\mathrm{GC} 2-\mathrm{ACP}+2,5 \%$ & ACP-101c $+2,5 \%$ gema de ovo de Galus gallus \\
\hline GOGD & domesticus \\
\hline $\begin{array}{l}\text { ACP: água de coco em pc } \\
\text { gallus domesticus. \%: perc } \\
\text { Fonte: Autores. }\end{array}$ & S: hidroximetil aminometano. GOGD: gema de ovo de Galus \\
\hline
\end{tabular}

Tabela 2. Descrição dos grupos experimentais.

\begin{tabular}{cc}
\hline Grupos experimentais & Concentrações/Descrição \\
\hline TRIS 2,5\% GONM & TRIS $+2,5 \%$ gema de ovo Numida meleagris \\
TRIS 5\% GONM & TRIS $+5 \%$ gema de ovo Numida meleagris \\
TRIS 10\% GONM & TRIS $+10 \%$ gema de ovo Numida meleagris \\
TRIS 15\% GONM & TRIS $+15 \%$ gema de ovo Numida meleagris \\
TRIS 20\% GONM & TRIS $+20 \%$ gema de ovo Numida meleagris \\
ACP 2,5\% GONM & ACP-101c $+2,5 \%$ gema de ovo Numida meleagris \\
ACP 5\% GONM & ACP-101c $+5 \%$ gema de ovo Numida meleagris \\
ACP 10\% GONM & ACP-101c $+10 \%$ gema de ovo Numida meleagris \\
ACP 15\% GONM & ACP-101c $+15 \%$ gema de ovo Numida meleagris \\
ACP 20\% GONM & ACP-101c $+20 \%$ gema de ovo Numida meleagris \\
\hline
\end{tabular}

ACP: água de coco em pó. TRIS: hidroximetil aminometano. GONM: gema de ovo de Numida meleagris. \%: percentual.

Fonte: Autores.

\subsection{Congelação/descongelação de sêmen}

Foram envasadas oito palhetas francesas de 0,25 mL (IMV Technologies, Campinas, São Paulo, Brasil) de cada grupo.

O processo de criopreservação foi realizado com auxílio do aparelho TK3000 ${ }^{\circledR}$ (TK Tecnologia em Congelação Ltda., Uberaba, Brasil), seguindo-se as instruções do fabricante, utilizando a curva rápida $\left(0,5^{\circ} \mathrm{C} / \mathrm{min}\right.$. até $5^{\circ} \mathrm{C} ; 15^{\circ} \mathrm{C} / \mathrm{min}$. até $-20{ }^{\circ} \mathrm{C}$ 
e $10^{\circ} \mathrm{C} / \mathrm{min}$. até $\left.-120^{\circ} \mathrm{C}\right)$. Posteriormente, as amostras foram imersas em nitrogênio líquido (-196 $\left.{ }^{\circ} \mathrm{C}\right)$ e, armazenadas em raques em botijões criogênicos.

\subsection{Avaliação da integridade do DNA pós-descongelação}

Após sete dias, procedeu-se a descongelação do sêmen para a análise da integridade do DNA dos espermatozoides caprinos, através do teste Cometa (“OpenComet”). A análise da integridade do DNA foi realizada no Laboratório de Mutagenicidade (LABMUT) do Núcleo de Pesquisa em Biotecnologia e Biodiversidade (NPBio) da Universidade Estadual do Piauí (UESPI), Teresina, Piauí, Brasil.

As amostras de sêmen foram descongeladas e $5 \mu \mathrm{L}$ foram acondicionados em microtubos contendo $75 \mu \mathrm{L}$ de agarose de baixo ponto de fusão $(1,5 \%)$ a $37^{\circ} \mathrm{C}$. Posteriormente, essa mistura foi homogeneizada e transferida para lâminas prérevestidas com agarose. Em seguida, as lâminas foram cobertas com lamínulas e colocadas a $3^{\circ} \mathrm{C}$ durante 20 min. Por fim, as lamínulas foram removidas e as lâminas foram imersas em solução de lise por 48 horas.

Na sequência, as lâminas foram colocadas em cuba de eletroforese contendo uma solução tampão, para a desnaturação do DNA. Foi realizada a eletroforese e as lâminas foram neutralizadas e, em seguida, secas e armazenadas para análise posterior. Finalmente, as lâminas foram coradas com brometo de etídeo $(20 \mathrm{mg} / \mathrm{mL})$ e cobertas com uma lamínula.

A avaliação das lâminas foi realizada em microscópio de imunofluorescência em um aumento de 40x, em ensaio cego. Posteriormente, foram contabilizadas 200 células por lâminas de cada concentração experimental (100 para cada exposiçãoaguda e crônica). As formas dos cometas seguiram um padrão estabelecido no laboratório. Foram utilizadas classes de 0 a 3 , sendo 0 nenhum dano e três, cauda do cometa superior a duas vezes o tamanho do nucleóide. A partir destes dados, foi calculado o Índice de Danos e a Frequência de Danos, variando de 0 (ausência de danos) até 100 (dano máximo).

\subsection{Avaliação ultraestrutural dos espermatozoides pós-descongelação}

A integridade morfológica das membranas e organelas dos espermatozoides pós-descongelação foi avaliada por microscopia eletrônica de transmissão (MET), no Instituto de Biociências da Universidade de Brasília (UnB), Brasília, Distrito Federal, Brasil.

O protocolo utilizado foi o de Burgess et al. (2001), em que as palhetas de sêmen foram descongeladas a $37{ }^{\circ} \mathrm{C}$ e lavadas em PBS a $37^{\circ} \mathrm{C}$. Em seguida, foram centrifugadas a $5.000 \mathrm{~g}$ e fixadas em glutaraldeído $(2,5 \%)$ em tampão fosfato $(0,1 \mathrm{M})$. Foram então pós-fixadas em tretóxido de ósmio em tampão fosfato, contrastadas em bloco com acetato de uranila (2,5\%), submetidas à desidratação em séries crescente de acetona (30\%, 50\%, 70\%, 90\% e 100\%) por 15 min. em cada etapa. Posteriormente, as amostras foram mantidas por 12 horas em mistura acetona e resina Epon. As amostras foram transferidas para resina pura onde ficaram por mais 12 horas. Finalmente foram incluídas em resina Epon (Sigma, St. Louis, MO, USA) em suporte de silicone e colocadas para polimerização em estufa a $65{ }^{\circ} \mathrm{C}$. Foram realizados cortes ultrafinos em ultramicrótomo EM UC6 (Leica, Wetzlar, Alemanha) em corte de $70 \mathrm{~nm}$. Os cortes foram coletados em grades de cobre e contrastados em acetato de uranila (5\%) por 1h15min e citrato de chumbo por 4 min, e estocado em dissecador até o momento da avaliação em MET (JEOL, modelo JEM 1011, Tóquio, Japão) equipado com câmara CCD Gatan (Califórnia, EUA).

\subsection{Análise estatística}

Foi utilizado um delineamento inteiramente casualizado (DIC). Foram obtidas as médias e desvio-padrão e procedida à análise de variância (ANOVA). Para a comparação das médias, foi utilizado o teste de Tukey, de acordo com o coeficiente de variação obtido, considerando um nível de significância de 5\%. Foi utilizado o PROC GLM (General Linear Models) do 
Software SAS® (Statistical Analysis System) para Windows versão 9.0. Na correlação estatística do ensaio cometa para o índice de dano ao DNA espermático pós-descongelação foi utilizado o teste de Mann-Whitney. As análises da avaliação espermática por microscopia eletrônica de transmissão foram apresentadas de forma descritiva.

\section{Resultados}

Neste estudo, avaliou-se a influência da fragmentação do DNA espermático (utilizando o teste Cometa) no sêmen caprino. Os resultados da análise do comprimento da cauda do DNA realizado pelo "OpenComet" (teste Cometa) dos espermatozoides caprinos estão demonstrados na Figura 1. Os dados informam o comprimento da cauda do DNA dos espermatozoides, cujo sêmen havia sido criopreservado em meio TRIS em diferentes concentrações de gema de ovo de Numida meleagris (GONM) e TRIS com 2,5\% de gema de ovo de Gallus gallus domesticus (GOGD - grupo controle) após análise pelo referido teste.

Quanto ao comprimento da cauda de DNA formada, não houve diferença significativa entre os grupos experimentais criopreservados em meio TRIS adicionados da gema de ovo de Numida meleagris (GONM) nas concentrações de 2,5\%; 5,0\%; e $10 \%$ quanto ao grupo controle (TRIS 2,5\% GOGD) ( $>0,05)$.

Observou-se ainda que o melhor grupo experimental, com mínima diferença significativa do grupo TRIS foi à GONM 2,5\%, semelhante ao TRIS 2,5\% da GOGD ( $>0,05)$. Logo quanto menor o comprimento da cauda, menor será o dano e menos genotóxico será o diluente, visando a manutenção da viabilidade dos espermatozoides.

Os grupos experimentais TRIS 15\% GONM e TRIS 20\% GONM apresentaram diferença significativa em relação ao grupo controle TRIS 2,5\% GOGD (P < 0,05). Logo, o comprimento da cauda do DNA foi maior no grupo experimental TRIS $20 \%$ GONM, de acordo como demonstrado na figura, sugerindo uma ação, provavelmente, mais lesiva e tóxica na viabilidade dos espermatozoides.

Figura 1. Registro do comprimento da cauda do DNA de espermatozoides caprinos criopreservado em TRIS adicionado de diferentes concentrações da gema de ovo de Numida meleagris pós-descongelação através da análise do "OpenComet".

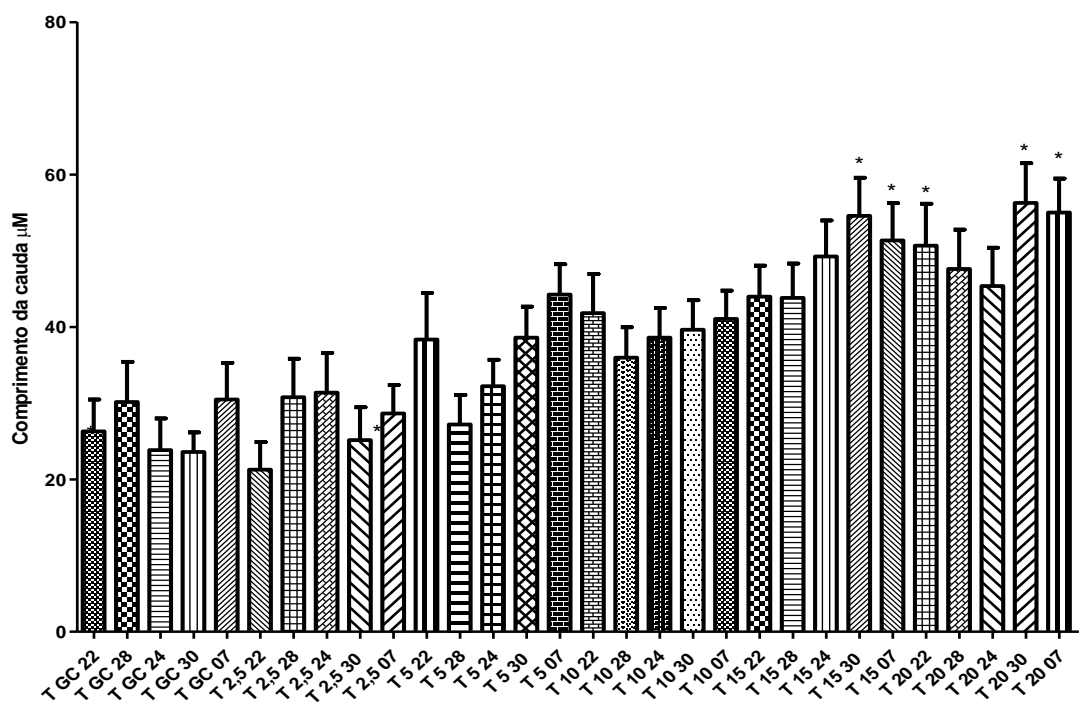

(*) comparado com o grupo controle (P < 0,05). T = TRIS; GC = Grupo Controle; Dias da coleta (22/08; 28/09; 24/10; 30/11; 07/12); \% das amostras dos grupos experimentais $(2,5 \% ; 5 \% ; 10 \% ; 15 \% ; 20 \%)$.

Fonte: Elaborada pelos autores (2021). 
Não houve diferença estatística quanto ao percentual de DNA na cauda nos grupos TRIS com 2,5\%; 5,0\%; e 20\% da GONM em comparação ao grupo controle TRIS 2,5\% GOGD (P > 0,05). Logo, o percentual de fragmentação do DNA foi semelhante entre os grupos mencionados (Figura 2).

Os grupos experimentais TRIS 10\% de GONM e TRIS 15\% de GONM apresentaram diferença estatística em relação ao grupo controle TRIS 2,5\% de GOGD (P < 0,05). Pois, o percentual de DNA na cauda foi superior no TRIS 10\% de GONM. Isso demonstra que essas células espermáticas não são viáveis para uso, inclusive, em biotecnologias reprodutivas, como a produção in vitro de embriões na etapa de fertilização in vitro e inseminação artificial, uma vez que apresentaram fragmentação do DNA, material genético indispensável para que a fecundação seja possível. Diante disso, ressalta-se que a concentração de 10\% de GONM não é indicada para a criopreservação de sêmen caprino. O melhor grupo experimental sem diferença significativa foi o TRIS 2,5\% de GONM.

Figura 2. Registro do percentual de fragmentação de DNA de espermatozoides caprinos criopreservado em TRIS adicionado de diferentes concentrações da gema de ovo de Numida meleagris pós-descongelação através da análise do "OpenComet”.

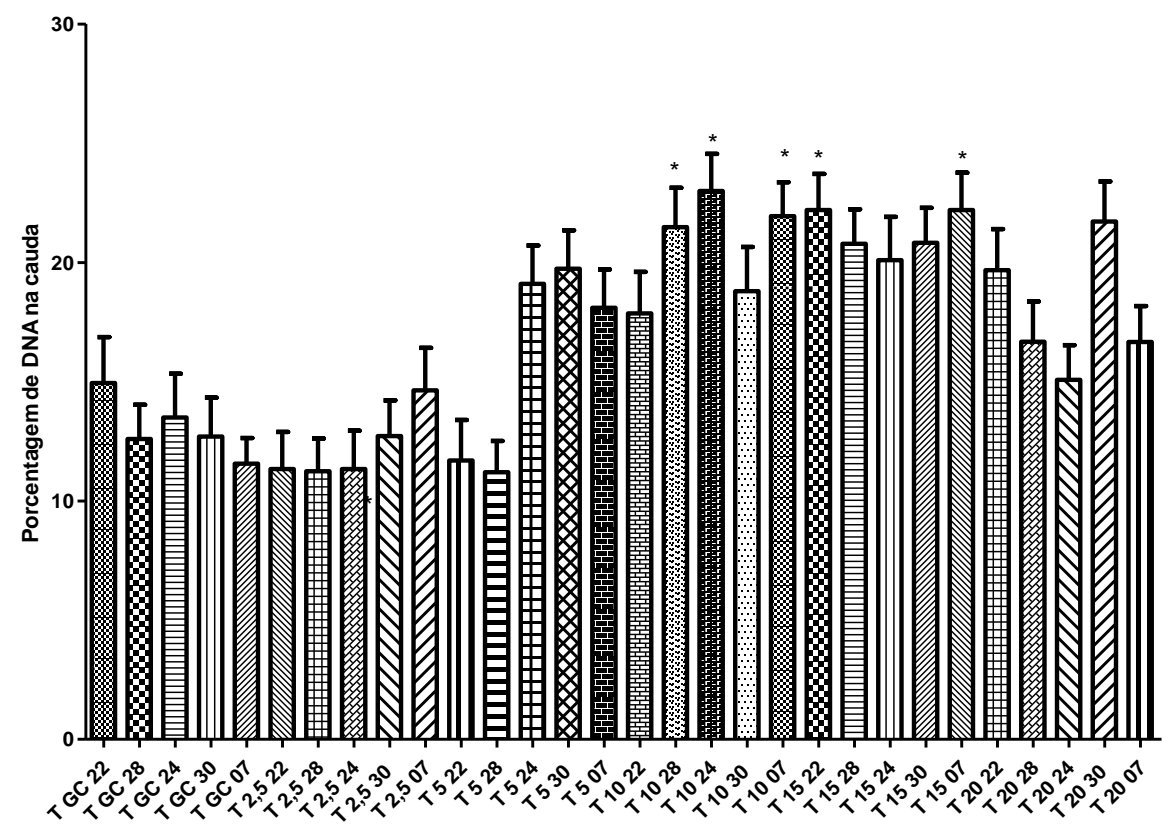

(*) comparado com o grupo controle $(\mathrm{P}<0,05)$. T = TRIS; GC = Grupo Controle; Dias da coleta (22/08; 28/09; 24/10; 30/11; 07/12); \% das amostras dos grupos experimentais $(2,5 \% ; 5 \% ; 10 \% ; 15 \% ; 20 \%)$.

Fonte: Elaborada pelos autores (2021).

Na Figura 3 observam-se os dados referentes ao grupo ACP-101c ${ }^{\circledR}$ em diferentes concentrações de GONM e ACP$101 \mathrm{c}^{\circledR}$ e grupo controle (2,5\% da GOGD), após análise pelo teste cometa.

Não foi verificada diferença estatística entre os grupos experimentais $\mathrm{ACP}^{\circledR}$ com $\mathrm{GONM}$ nas concentrações de $2,5 \%$ e $5 \%$ em comparação ao grupo controle (GOGD 2,5\%) $(\mathrm{P}>0,05)$.

$\mathrm{O}$ grupo $\mathrm{ACP}^{\circledR} 2,5 \% \mathrm{GONM}$ apresentou melhor viabilidade das células espermáticas, apresentando menor diferença ao grupo controle $\mathrm{ACP}^{\circledR} 2,5 \%$ GOGD (P > 0,05). O grupo $\mathrm{ACP}^{\circledR} 5 \%$ GONM apresentou comprimento de cauda de DNA maior do que o grupo controle $(\mathrm{P}>0,05)$. 
Os grupos experimentais $\mathrm{ACP}^{\circledR}$ com 10\%, 15\% e $20 \%$ de GONM apresentaram comprimento de cauda de DNA maior, sendo considerados menos propícios e genotóxico à criopreservação do sêmen caprino, apresentando diferença significativa $(P>0,05)$.

Não houve diferença significativa entre os grupos experimentais $\mathrm{ACP}^{\circledR}$ com GONM nas concentrações de 2,5\% e 5\% em comparação ao grupo controle (GOGD 2,5\%) com relação ao tamanho da cauda de DNA nos espermatozoides caprinos criopreservados em ACP-101c ${ }^{\circledR}(\mathrm{P}>0,05)$.

Figura 3. Registro do comprimento da cauda do DNA de espermatozoides caprinos criopreservado em ACP-101c ${ }^{\circledR}$ adicionado de diferentes concentrações da gema de ovo de Numida meleagris pós-descongelação através da análise do "OpenComet".

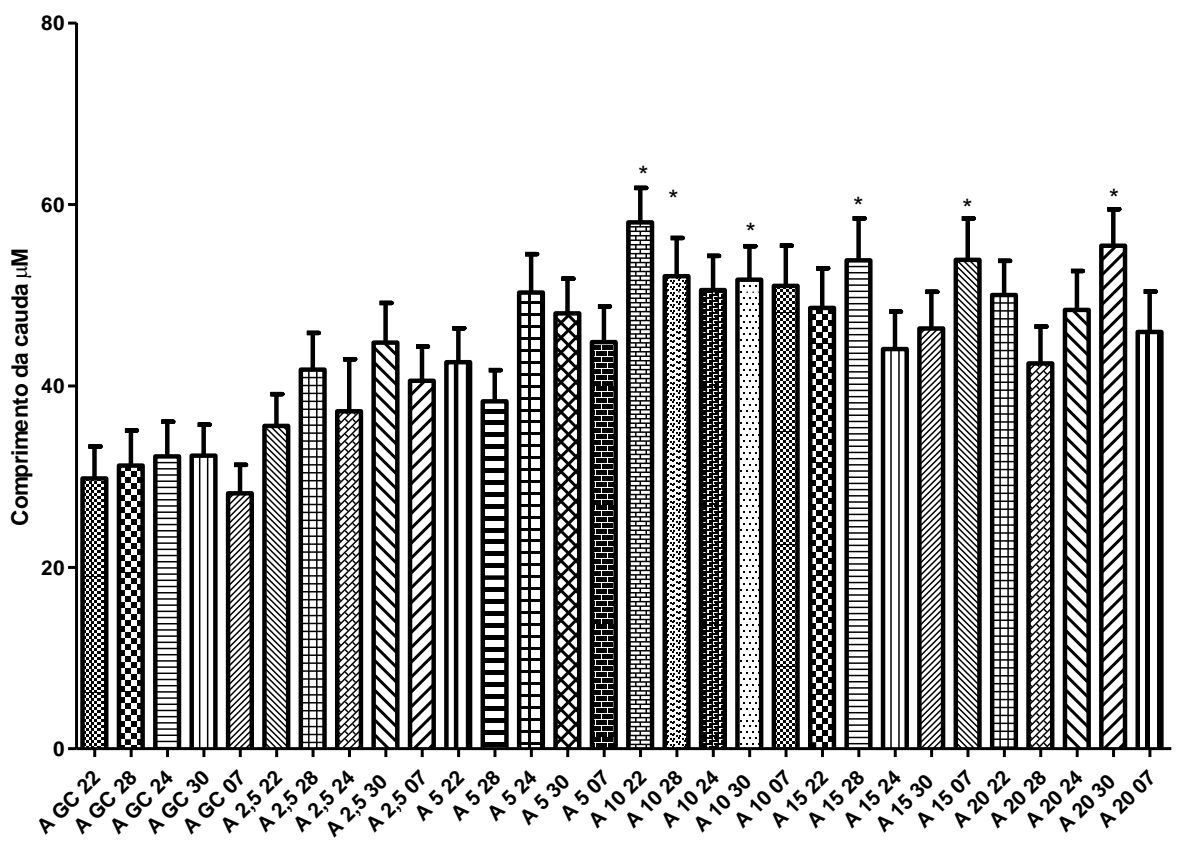

(*) comparado com o grupo controle $(\mathrm{P}<0,05)$. A = ACP-101c®; GC = Grupo Controle; Dias da coleta (22/08;28/09;24/10;30/11;07/12); $\%$ das amostras dos grupos experimentais $(2,5 \% ; 5 \% ; 10 \% ; 15 \% ; 20 \%)$.

Fonte: Elaborada pelos autores (2021).

Na Figura 4 os grupos experimentais $\mathrm{ACP}^{\circledR}$ com 10\%, 15\% e 20\% da GONM foram considerados menos propícios à criopreservação do sêmen caprino, por apresentarem porcentagens, maiores com baixa viabilidade para os espermatozoides quando comparado ao grupo controle $A C P^{\circledR} 2,5 \% \operatorname{GOGD}(P<0,05)$ e ao grupo experimental com $A C P^{\circledR} 2,5 \%$ e $5 \%$ de GONM. 
Figura 4. Registro da porcentagem de DNA na cauda após análise do "OpenComet" de espermatozoides caprinos criopreservado em ACP-101c ${ }^{\circledR}$ adicionado de diferentes concentrações da gema de ovo de Numida meleagris pósdescongelação.

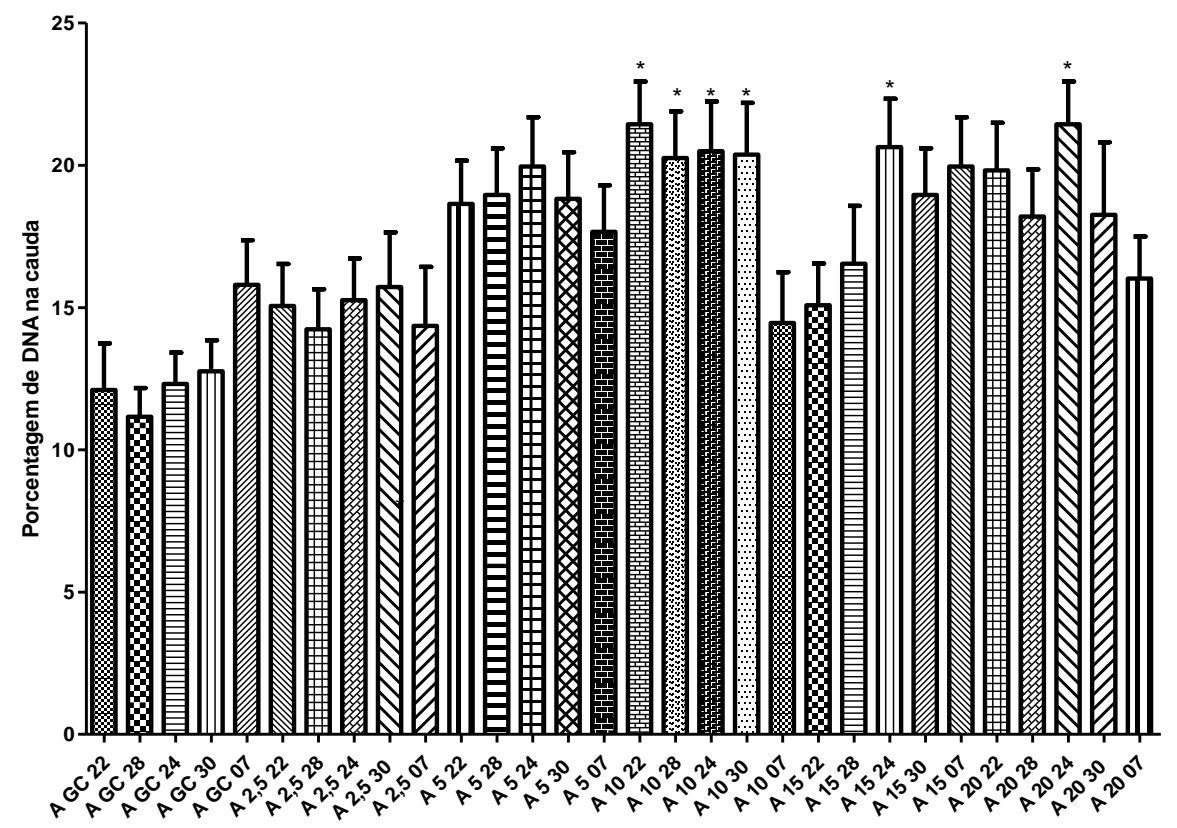

(*) comparado com o grupo controle $(\mathrm{P}<0,05) . \mathrm{A}=\mathrm{ACP}-101 \mathrm{c}(\mathrm{B} ; \mathrm{GC}=$ Grupo Controle; Dias da coleta $(22 / 08 ; 28 / 09 ; 24 / 10 ; 30 / 11 ; 07 / 12)$; $\%$ das amostras dos grupos experimentais $(2,5 \% ; 5 \% ; 10 \% ; 15 \% ; 20 \%)$.

Fonte: Elaborada pelos autores (2021).

Nas Figuras de 5 a 9 observam-se as ultraestruturas das células espermáticas pós-descongelação em microscopia eletrônica de transmissão (MET).

Nas Figuras 5 e 6 foi realizada análise ultraestrutural dos espermatozoides após descongelação, os quais foram criopreservados em meio ACP-101c ${ }^{\circledR}$ adicionado de 2,5\% de GOGD, por meio de microscopia eletrônica de transmissão. Na Figura 5, referente ao grupo controle, foi possível verificar poucas alterações estruturais nas amostras analisadas, contudo, identificou-se na região do flagelo um deslocamento da membrana plasmática que o recobre. Na Figura 6, em amostras desse mesmo grupo, foram identificadas regiões afetadas, sugerindo que houve influência negativa do processo de criopreservação para a ocorrência das injúrias. 
Figura 5. Análise ultraestrutural de espermatozoides após descongelação, os quais foram criopreservados em meio ACP-101c ${ }^{\circledR}$ adicionado de 2,5\% de gema de ovo de Gallus gallus domesticus (grupo controle), por meio de microscopia eletrônica de transmissão.

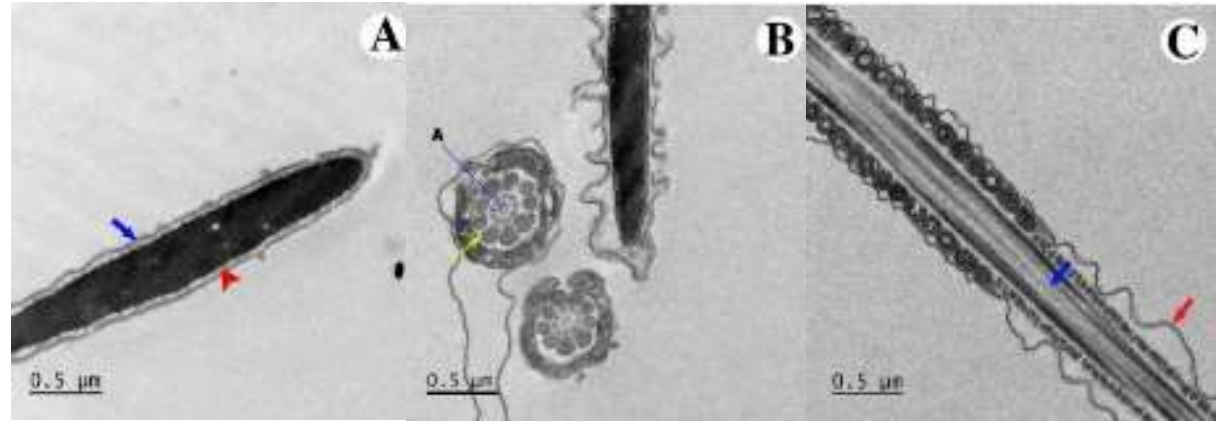

Na imagem A, observa-se a membrana plasmática (seta azul), região acrossomal e cromatina preservadas (cabeça de seta vermelha). Na imagem B, verifica-se a transição entre peça intermediária e flagelo, colar mitocondrial preservado com as organelas intactas e axonema (letra A), também preservado, com elementos do citoesqueleto visíveis e de aspecto usual (seta amarela). Na Imagem $\mathbf{C}$, verifica-se região do flagelo em corte longitudinal onde se observa a disposição dos microtúbulos de aspecto usual (seta azul). No entanto, ainda nesta região se observa um deslocamento da membrana compatível com região terminal do flagelo (seta vermelha).

Fonte: Fotografia de propriedade dos autores (2021).

Figura 6. Análise ultraestrutural de espermatozoides caprinos após descongelação, os quais foram criopreservados em ACP$101 \mathrm{c}^{\circledR}$ adicionado de 2,5\% da gema de ovo de Gallus gallus domesticus (grupo controle), através de microscopia eletrônica de transmissão.

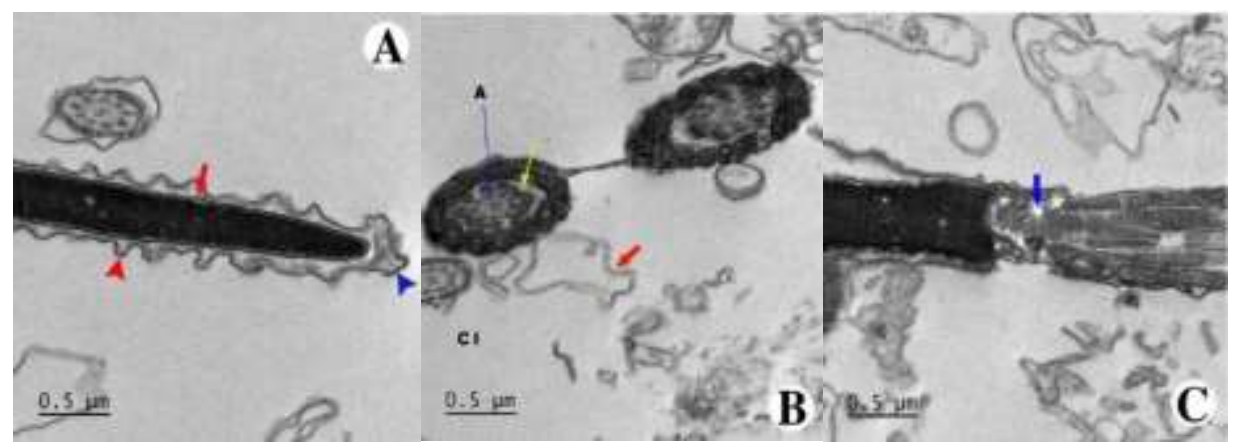

Na imagem A, demonstra-se associação de membrana frouxa em torno da célula (cabeça de seta azul). São identificados também pontos de deslocamento da cromatina (seta vermelha), esta ondulação de membrana é condizente com regiões de edema (cabeça de seta vermelha). Região acrossomal desorganiza (seta vermelha). Na imagem B, observa-se corte transversal da peça intermediária em transição com flagelo, a seta amarela demonstra o colar de mitocôndrias preservado e região de axonema típica com elementos de microtúbulo (letra A), seta vermelha demonstra apenas fragmentos. Na imagem $\mathbf{C}$, demonstra-se a região de centríolos preservada com ultraestrutura típica para corte transversal (seta azul).

Fonte: Fotografia de propriedade dos autores (2021).

Na Figura 7 observa-se o resultado da análise ultraestrutural dos espermatozoides após descongelação, os quais foram criopreservados em meio ACP-101 $\mathrm{c}^{\circledR}$ adicionado de $10 \%$ de GONM, por meio de microscopia eletrônica de transmissão. Nessa amostra, foi identificado um elevado grau de degradação nos componentes ultraestruturais, sendo indicativo de baixa atividade de preservação do meio utilizado no processo de criopreservação. Dessa forma, não recomendando-o para criopreservação de sêmen caprino. 
Figura 7. Análise ultraestrutural de espermatozoides após descongelação, os quais foram criopreservados em $\mathrm{ACP}-101 \mathrm{c}^{\circledR}$ adicionado de $10 \%$ da gema de ovo de Numida meleagris, por meio de microscopia eletrônica de transmissão.

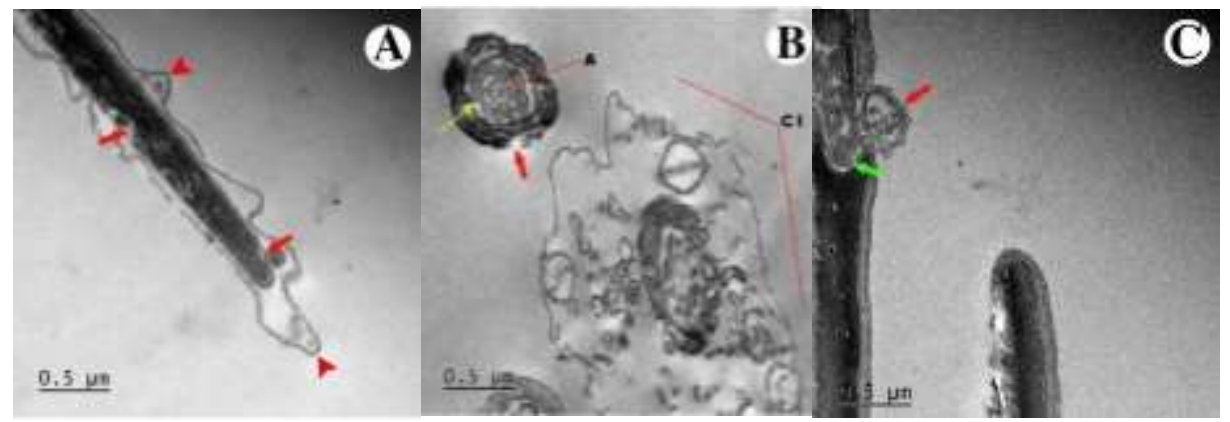

$\mathrm{Na}$ imagem A, demonstra-se diversas protrusões de membrana, o que evidencia descolamento da membrana na região da cabeça do espermatozoide (cabeças de setas vermelhas). Ainda nessa região, a cromatina apresenta áreas de esvaziamento (setas vermelhas). São visualizados elementos eletrondensos se desprendendo da célula. Na imagem $\mathbf{B}$, região de transição da peça intermediária com o flagelo, apresentando colar mitocondrial preservado com axonema também preservado (letra A e seta amarela), presença debris celulares (CI). Na imagem $\mathbf{C}$, região de centríolo com alterações morfológicas atípicas (seta verde), condensação de elementos eletrondensos confinados em unidades de membrana se projetando para fora da estrutura do flagelo (seta vermelha).

Fonte: Fotografia de propriedade dos autores (2021).

Na Figura 8 observa-se o resultado da análise ultraestrutural dos espermatozoides caprinos após descongelação, os quais foram criopreservados em ACP-101c ${ }^{\circledR}$ adicionado de 2,5\% GONM, através de microscopia eletrônica de transmissão. Dentre os achados na ultraestrutura celular, vale inferir que a célula espermática apresentou várias regiões preservadas, com apenas uma alteração na região abaixo do centríolo, apresentando pequenas vesículas indicativas de degeneração celular e perda de estabilidade estrutural da cauda do espermatozoide. Resultado este, melhor do que o encontrado no grupo experimental ACP-101c ${ }^{\circledR}$ adicionado de 10\% de GONM (Figura 7).

Figura 8. Análise ultraestrutural de espermatozoides caprinos após descongelação, os quais foram criopreservados em ACP$101 \mathrm{c}^{\circledR}$ adicionado de $2,5 \%$ da gema de ovo de Numida meleagris, através de microscopia eletrônica de transmissão.

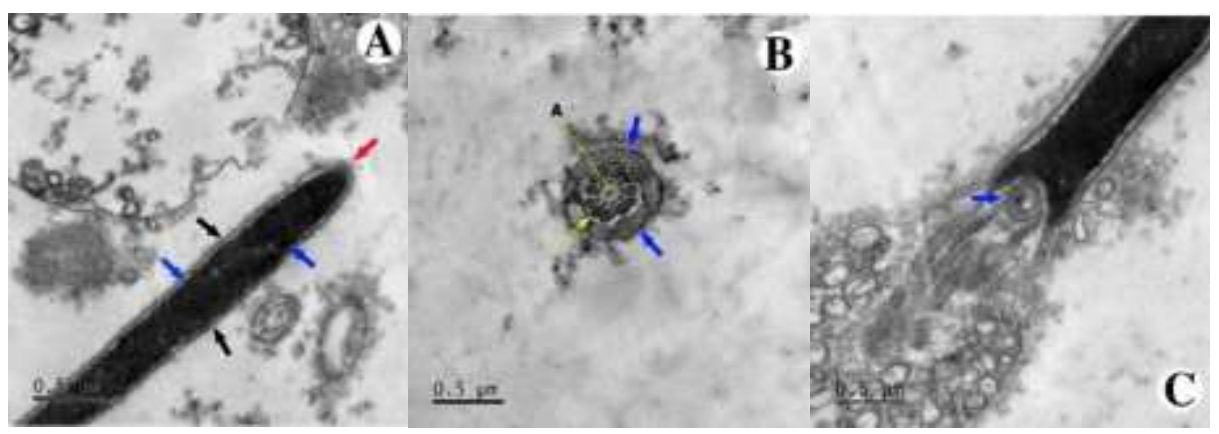

Na imagem A, demonstra-se região de cabeça preservada, membranas íntegras com acrossoma preservado (setas pretas e seta vermelha). Cromatina íntegra e com aspecto ultraestrutural normal em corte longitudinal (setas azuis). Na imagem B, verificase a região de transição entre a peça intermediária e flagelo. Mitocôndrias preservadas. Microtúbulos periféricos (seta amarela) e microtúbulos centrais (letra A); axonema preservado (setas azuis). Na imagem $\mathrm{C}$, demonstra-se centríolo parcialmente preservado em corte longitudinal (seta azul). A região abaixo do centríolo contém diversas pequenas vesículas indicativas de degeneração celular e perda de estabilidade estrutural da cauda do espermatozóide. Essa amostra mostrou-se preservada, no entanto foram encontradas células contendo desestruturação na região flagelar.

Fonte: Fotografia de propriedade dos autores (2021). 
Na Figura 9, observa-se o resultado da análise ultraestrutural dos espermatozoides caprinos após descongelação, os quais foram criopreservados em ACP-101c ${ }^{\circledR}$ adicionado de 2,5\% GOGD através de microscopia eletrônica de transmissão. Nessa amostra do grupo controle foram evidenciadas alterações em nível de membrana e cromatina, embora, outras regiões importantes da célula espermática estivessem preservadas. Vale salientar que o acrossoma apresentou ultraestrutura bem preservada, tendo em vista ser uma organela importantíssima para o processo de fertilização, pois alberga enzimas hidrolíticas responsáveis pela penetração da célula espermática na zona pelúcida, fenômeno conhecido como reação acrossomal.

Figura 9. Análise ultraestrutural de espermatozoides caprinos após descongelação, os quais foram criopreservados em ACP$101 \mathrm{c}^{\circledR}$ adicionado de 2,5\% da gema de ovo de Gallus gallus domesticus (grupo controle), através de microscopia eletrônica de transmissão.

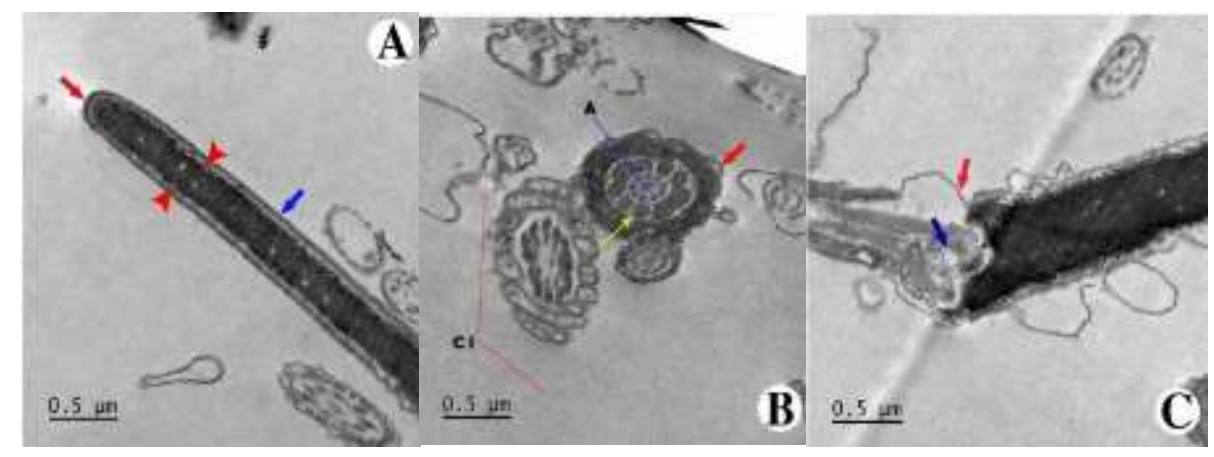

$\mathrm{Na}$ imagem A, demonstra-se a cabeça do espermatozoide em corte transversal onde se observa a membrana e acrossoma com aspectos ultraestruturais bem preservados (seta azul e seta vermelha). Cromatina com deslocamento de membrana e cromatina apresentando pontos eletronlúcidos, indicando perda de material (cabeças de seta vermelha). Na imagem B, observa-se a região de transição entre a peça intermediária e flagelo, onde verifica-se deslocamento de membrana (seta vermelha) e colar de mitocôndrias com axonema e ultraestrutura conservada (seta amarela). Nessa imagem é possível visualizar um grande número de células degradadas representadas pelos diversos debris celulares (CI). Na imagem C, demonstra-se a região de centríolo com alterações ultraestruturais importantes indicadas pelo descolamento da membrana (seta vermelha) e regiões anormais eletronlucentes dentro do centríolo (seta azul) com presença de estruturas membranares circulares e mitocôndrias laterais degeneradas.

Fonte: Fotografia de propriedade dos autores (2021).

\section{Discussão}

De acordo com os resultados obtidos, neste estudo, quanto a avaliação do nível de fragmentação espermática pelo teste cometa, foi possível identificar a importância de sua realização, principalmente, quando com as amostras foram congeladas/descongeladas. Fato este ratificado por Andrabi (2007), sendo o teste cometa capaz de estimar com precisão o percentual de espermatozoides com danos na cromatina, o que prejudica a viabilidade da célula, sobretudo, a capacidade fertilizante. Ademais, salienta-se a importância dessa técnica na seleção de sêmen a ser utilizado em programas de inseminação artificial e fertilização in vitro (Sakkas et al., 2004).

O processo de criopreservação pode gerar aumento de espécies reativas de oxigênio (EROS) o que contribui significativamente, segundo Simões (2013), para a fragmentação do DNA espermático. Além dessa causa, existem outras, como, por exemplo, a deficiência de protamina, apoptose espermática (Simões, 2013).

Segundo Silva et al. (2018), a microscopia eletrônica de transmissão é uma ferramenta utilizada para determinar o tamanho e a forma das estruturas orgânicas (biológicas) e inorgânicas. Baseia-se na interação dos elétrons incidentes sobre a matéria. E isso foi encontrado neste estudo.

Na imagem A da Figura 5, as alterações de cromatina estão geralmente associadas às alterações morfológicas e, consequentemente, de motilidade (Enciso et al., 2011). Perdrix et al. (2011), verificaram que a presença de vacúolos com 
tamanho superior a $13 \%$ da área total da cabeça não tem relação com a fragmentação do DNA. Dados semelhantes foram encontrados no estudo realizado por Moura et al., (2013).

Essas degradações podem estar associadas a anomalias de acrossoma (Kacem et al., 2010; Perdrix et al., 2011; Lavolpe et al., 2015). Por outro lado, esses vacúolos, quando ocupam mais de 50\% da superfície nuclear, têm sido associados ao aumento na fragmentação e desnaturação de DNA (Garolla et al., 2008; Franco et al., 2011), apresentando consequentemente baixa eficiência nas técnicas de reprodução assistida (Berkovitz et al., 2006).

A avaliação qualitativa da ultraestrutura dos espermatozoides por meio da microscopia eletrônica de transmissão possibilita identificar danos espermáticos (Silva et al., 2013), uma vez que abrange os dados de informações não visíveis e perceptíveis na análise por microscopia óptica simples.

$\mathrm{Na}$ análise ultraestrutural por microscopia eletrônica de transmissão, neste estudo, não foram verificadas ações deletérias nos grupos controle e experimentais. As regiões da cabeça (membrana plasmática e acrossoma) mantiveram-se preservadas, sem alteração no DNA. As lesões de cabeça e cauda foram semelhantes às descritas para espermatozoides caprinos, mesmo estes apresentando tamanho, forma e composição lipídica distintas (Purdy, 2006).

De acordo com o estudo desenvolvido por Ciftci; Zulkadir (2010) a avaliação nuclear do espermatozoide por meio da microscopia eletrônica de transmissão é realizada apenas em uma secção da cabeça, uma vez que o corte feito na amostra possui entre 50 e $100 \mathrm{~nm}$; enquanto que a cabeça do espermatozoide possui dimensão aproximada de $14 \mu \mathrm{m}$ em seu diâmetro maior, e $7 \mu \mathrm{m}$ em seu diâmetro menor.

A microscopia eletrônica de transmissão é uma ferramenta muito útil para avaliação de células, permitindo visualizar detalhes (com grande aumento e resolução) não vistos em outras técnicas. Apesar disso, em alguns casos, como na avaliação da cromatina nuclear de espermatozoides, por limitar a visualização apenas a uma secção da cabeça, faz-se necessário a utilização de uma grande amostra para tornar a avaliação confiável.

\section{Conclusão}

A gema de ovo de Numida meleagris, como crioprotetor adicionado aos meios diluentes ACP-101c ${ }^{\circledR}$ e TRIS, é um componente inédito, que tem resultados promissores na concentração de 2,5\%, para a criopreservação do sêmen caprino. No entanto, não se exclui a necessidade de mais estudos para maior investigação e consequente validação desse componente.

\section{Referências}

Alvarez-Suarez, J. M., Tulipani, S., Díaz, D., Estevez, Y., Romandini, S., Giampieri, F., Damiani, E., Astolfi, P., Bompadre, S., \& Battino, M. (2011). Antioxidant and antimicrobial capcity of several monofloral Cuban honeys and their correlation with color, polyphenol content and other chemical compounds. Food and Chemical Toxicology. 48, 2490-2499.

Andrabi, S. M. S. (2007). Mammalian sperm cromatin structure and assessment of DNA fragmentation. Journal of assisted reproduction and genetcs. 24, 561569.

Berkovitz, A., Eltes, F., Lederman, H., Peer, S., Ellenbogen, A., Feldberg, B., \& Bartoov, B. (2006). How to improve IVF-ICSI outcome by sperm selection. Reproductive Biomedicine Online. 12, 5, 634-638.

Burgess, C. M., Bredl, J. C. S., Plummer, J. M., \& Inglaterra, G. C. (2001). Vital and ultrastructural changes in dog spermatozoa during cryopreservation. J. Reprod. Fertil. 57, 357-363.

Brianezi, G. S., Camargo, J. L. V., \& Miot, H. A. (2009). Desenvolvimento e validação de técnica quantitativa de análise de imagem para avaliação do teste do Cometa corado pela prata. Jornal Brasileiro de Patologia e Medicina Laboratorial. 45(4), 325-334.

Ciftci, H. B.; \& Zulkadir, U. (2010). The correlation between bull sperm head dimensions and mitochondrial helix length. Journal of Animal and Veterinary Advances. 9(7), 1169-1172.

Colégio Brasileiro de Reprodução Animal, Manual de exame andrológico, $2^{\circ}$ Ed, Belo Horizonte, Brasil, 2013. 
Enciso, M., Cisale, H., Johnston, S. D., Sarasa, J., Fernandez, J. L., \& Gosálvez, J. (2011). Major morphological sperm abnormalities in the bull are related to sperm DNA damage. Theriogenology. 76(1), 23-32.

Franco, J. G. Jr., Mauri, A .L., Petersen, C. G., Massaro, F.C., Silva, L. F. I., Felipe, V., Cavagna, M., Pontes, A., Baruffi, R. L. R., Oliveira, J. B. A., \& Vagnini, L. D. (2011). Large nuclear vacuoles are indicative of abnormal chromatin packaging in human spermatozoa. International Journal of Andrology. $35(1), 46-51$

Garolla, A., Fortini, D., Menegazzo, M., De Toni, L., Nicoletti, V., Moretti, A., Selice, R., Engl, B., \& Foresta, C. (2008). High-power microscopy for selecting spermatozoa for ICSI by physiological status. Reproductive Biomedicine Online. 17(5), 610-616.

Kacem, O., Sifer, C., Barraud-Lange, V., Ducot, B., De Ziegler, D., Poirot, C., \& Wolf, J. (2010). Sperm nuclear vacuoles, as assessed by motile sperm organellar morphological examination, are mostly of acrosomal origin. Reproductive Biomedicine Online. 20, 132-7.

Lavolpe, M., Lorenzi, D., Greco, E., Nodar, F., \& Sedó, C.A. (2015). Relationship Between Sperm DNA Fragmentation and Nuclear Vacuoles. JBRA Assisted Reproduction, 19(2), 70-74.

Moura, C. S., Nunes, A. K. S., Silva, B. S., Peixoto, C. A., Silva A. R., Silva, S. V., \& Gerra, M. M .P. (2013). Efeito da temperatura de descongelação na integridade de espermatozoides criopreservados de cães. Arquivo Brasileiro de Medicina Veterinária e Zootecnia. $65,4$.

Park, S. Y., \& Choi, J. (2007). Cytotoxicity, genotoxicity and ecotoxicity assay using human cell and environmental species for the screening of the risk from pollutant exposure. Environmental International. 33, 817-822.

Perdrix, A., Travers, A., Chelli, M .H., Escalier, D., Rego, J. L., Milazzo, J .P., Moussetsiméon, N., Macé, B., \& Rives, N. (2011). Assessment of acrosome and nuclear abnormalities in human spermatozoa with large vacuoles. Human Reproduction. 26, 47-58.

Purdy, P. H. (2006). A review on goat sperm cryopreservation. Small Ruminant Ressearch. 63, 215-225.

Watt, B.; \& Merrill, A. L. (1963). Composition of foods: raw, processed, prepared. Washington: Consumer and Food Economics Research Division. 198.

Zaia, M. G. Efeito da Mentha peperita L. durante a infecção experimental por Schistosoma mansoni. (2015). Dissertação (Mestrado em Genética Evolutiva e Biologia Molecular) 89 f. - Universidade Federal de São Carlos, São Carlos, 2015.

Qin, Y.; Yang, S.; Xu, J.; Xia, C.; Li, X.; An, L.; \& Tian, J. (2018). Deep insemination with sex-sorted Cashmere goat sperm processed in the presence of antioxidants. Reproduction in domestic animals. 53(1), 11-19.

Rufino, M .S. M., Alves, R. E., Brito, E. S., Pérez-Jiménez, J., Saura-Calixto, F., \& Mancini-Filho, J. (2010). Bioactive compounds and antioxidant capacities of 18 non-traditional tropical fruits from Brazil. Food Chemistry. 121, 996-1002.

Sakkas, D., Seli, E., Manicardi, G. C.; Nijs, M., Ombelet, W., \& Bizzaro, D. (2004). The presence of abnormal spermatozoa in the ejaculate: did apoptosis fail. Humam Fertility. 7, 99-103.

Salgueiro, C. C. M., \& Nunes, J. F. (2012). Água de coco em pó em biotécnicas da reprodução de caprinos. Ciência Animal. $22(1)$, $20-32$.

Simões, R., Feitosa, W. B., Siqueira, A .F. P., Nichi, M., Paula-Lopes, F. F., Marques, M. G., Peres, M. A., Barnabe, V. H., Visintin, J. A., \& Assumpçao, M. E. O. (2013). Influence of bovine sperm DNA fragmentation and oxidative stress on early embryo in vitro development outcome. Reproduction. 146, 433-441.

Silva, H. V. R., Nunes, T. G. P., Mota Filho, A. C., Pinto, J. N., Silva, A. R., \& Silva, L .D. M. (2018). Adição de hidroxitolueno butilado (bht) no diluidor acp-106c para congelação de sêmen canino. Ciência Animal Brasileira. 19, 1-9.

Silva, M. A., Peixoto, G. C. X., Castelo, T.S., Lima, G.L., Silv, A.M., Oliveira, M.F., \& Silva, A.R. 2013. Cryopreservation of collared peccary (Pecari tajacu) semen using different freezing curves, straw sizes, and thawing rates. Cryobiology. 67(1), 50-55.

Silva, S.V., \& Guerra, M. M. P. (2011). Efeitos da criopreservação sobre as células espermáticas e alternativas para redução das crioinjúrias. Revista Brasileira de Reprodução Animal. 35, 370-384. 